\title{
Influential Factors and Strategy of Sustainable Product Development under Corporate Social Responsibility in Taiwan
}

\author{
Jui-Che Tu, ${ }^{1}$ Pi-Lien Chiu, ${ }^{1,2}$ Yu-Chen Huang, ${ }^{1}$ and Chuan-Ying Hsu ${ }^{3}$ \\ ${ }^{1}$ Graduate School of Design Doctoral Program, National Yunlin University of Science and Technology, Yunlin County 640, Taiwan \\ ${ }^{2}$ Department of Product Design, Tung-Fang Design Institute, Kaohsiung 829, Taiwan \\ ${ }^{3}$ Department of Business Administration, Dayeh University, Changhua City 515, Taiwan
}

Correspondence should be addressed to Jui-Che Tu; tujc@yuntech.edu.tw

Received 28 September 2013; Accepted 16 October 2013

Academic Editor: Teen-Hang Meen

Copyright (C) 2013 Jui-Che Tu et al. This is an open access article distributed under the Creative Commons Attribution License, which permits unrestricted use, distribution, and reproduction in any medium, provided the original work is properly cited.

\begin{abstract}
This study aimed to adopt the perspective of corporate social responsibility (CSR) to explore the intention of sustainable product development in Taiwan, as well as leading to the creation of influential factors that affect corporate sustainable product development intention. In this research, the induction analysis was conducted to understand the implementation of sustainable product development, and this was supplemented with questionnaire surveys and in-depth interviews to evaluate developmental intention. In addition, principal component analysis was used for factor analysis and content analysis in the $6 \mathrm{~W}$ expression method, leading to the creation of the influential factors. The research results have demonstrated that the factors affecting the intention of corporate sustainable product development include having a sustainable design and a development purpose, a corporate development purpose, sustainable development concepts, a sustainable design value, a sustainability concept, and a manufacturing process quality. For sustainable product development, corporate social responsibility needs to be most concerned with the added value of products, regulation requirements, and accommodation of the industrial chain, costs, and quality.
\end{abstract}

\section{Introduction}

In modern society, the concept of sustainable development is based on three factors, which are economic development, environmental conservation, and social justice. While pursuing new economic development models, the long-term sustainable development should not be neglected for shortterm individual benefits. In economic development, the environmental load should be balanced and buffered, and the natural resources and environments needed by human beings should be well protected, instead of abusing environmental resources. Development should be accompanied by contribution to the society; thus, there should be a balanced model of sustainable development based on the economy, environment, and society in order to accomplish sustainable development in human society $[1,2]$.

As corporate social responsibility (CSR) is gradually valued, firms usually have to deal with difficult problems regarding green issues in corporate sustainable development. Regarding environmental pollution caused by $3 \mathrm{C}$ electronic products in particular, firms should try to undertake CSR, while simultaneously achieving greater successful and stable sustainable development in design. Since the issues of global warming and climatic change become important, countries around the globe value the importance of constructing green civilization, and related measures of environmental protection become more complete [3]. The establishment of environmentally friendly green industry policies, finance policies, and tax policies and the enhancement of laws of environmental protection and complete management system result in harmony between human beings and nature, and they are important policies for the present and future of different countries $[4,5]$. Therefore, while the government actively reviews overall economic direction and implements new tax reform, firms should more positively implement sustainable development and product sustainable development design.

The corporate cognition and practice of social responsibility have evolved from a narrow to a broad sense. In Europe, Japan, and the USA, the concept of the corporate social 
citizen has become common. However, in Taiwan, the concept of CSR is still new. Therefore, when overseas cognition of CSR makes progress, firms in Taiwan are still at the level of charities and fundamental associations $[6,7]$. Regarding firms' difficulties in implementation of sustainable development, $53.4 \%$ of firms suggest the lack of a guidance mechanism, 50.9\% suggest that costs are too high, $38.8 \%$ suggest the existence of ambiguous governmental laws, and $35.3 \%$ indicate a lack of related professional knowledge. As to corporate sustainable development policy in regards to green business policy, $90.5 \%$ of firms suggest the importance of resource recovery, $83.6 \%$ use energy-saving devices, and $61.2 \%$ identify with the improvement of production [8].

Regarding positive development upon CSR, firms should not only be familiar with international laws and have significant support and guidance from government, but they should also possess the concepts of sustainable development, positive professional sustainable development, and responsive ability. However, firms sometimes cannot fulfill this responsibility due to a lack of management time and the traditional profitoriented concept of business [9, 10], and they tend to be passive and careless regarding sustainable development. However, nowadays, with green trends, sustainable products should be based on the concerns of development procedures, including material selection, manufacturing, innovation, assembly, transportation, dismantling, and recycling. Firms should try to obtain a balance in sustainable development within this trend in order to enhance corporate image in the market after product sustainable development [11-13].

For successful sustainable development, at the decisionmaking stage, firms must consider the impact on the environment, the direction after green product manufacturing, and the resulting waste. They must notice the demonstration of CSR and the increase of public consciousness of sustainability [14]. Therefore, in sustainable development, besides the sustainable perspective, they should consider the issues important for consumers and future trends, including corporate social image, positive attitude, and acceptance regarding corporate sustainable development in order to further recognize the important trend of sustainable development [15-17]. Firms must then explore the different degrees of implementation in decision-making of sustainable development, developmental intention, and difference, which will not only enhance firms' sustainable product development intention but will also solve the problems encountered during development. Therefore, firms, consumers, and social environments will be sustainable and developed by mutual dependency [18-20]. This study will analyze and conduct cross-comparison on the investigation of CSR, the degree of corporate product sustainable development, and the factors. Finally, the researcher constructs influential factors and strategy of sustainable product development as the criterion for the implementation of other related firms. Thus, based on the above analysis, this study aimed to explore correlation and effects of current corporate-developed sustainable products and the effects of sustainable product development intention.

Using interviews, this study probed into CSR and the current situation of corporate sustainable product development. In addition, it analyzed and conducted cross-comparisons of the impact factors. Finally, a coping model was constructed for corporate sustainable product development. The findings can serve as references for the implementation of corporate development of sustainable products.

\section{Research Structure and Method}

2.1. Research Structure. This study first reviewed their literatures related to CSR and sustainable product development in order to explore the correlation between CSR and sustainable product development. Secondly, using a questionnaire survey and in-depth interviews, this study investigated current sustainable product development under CSR and conducted an intention survey. SPSS was used to practice frequency distribution and factor analysis in order to establish factor analysis of the factors of sustainable product development under CSR. Content analysis of $6 \mathrm{~W}$ was conducted to explore the current sustainable product development under CSR. Finally, the results of the above two surveys and the literature review were generalized to propose future development intentions of sustainable product development under CSR and to construct an interactive influential model of sustainable product development under CSR (Figure 1).

2.2. Research Subjects. In order to explore the current situation and intentions of sustainable product development under CSR, the factors of different dimensions are investigated in this study. The research subjects investigated were experts in product design, management, and marketing as well as design strategy in the most representative and largescale enterprises among the $3 \mathrm{C}$ industries in Taiwan such as ASUSTeK Computer, Inc. (ASUS), Chi Mei Optoelectronics Corporation, Hewlett-Packard Development Company (HP), and National Council for Sustainable Development Network, as illustrated in Table 1, and these top four enterprises all practice a CSR system. The research subjects include four senior product designers, three product marketing managers, and one development strategy director. A questionnaire survey and in-depth interviews were conducted to acquire in-depth and valid data. In addition, a number of representative research institutes from the National Council for Sustainable Development Network are also interviewed to obtain information and suggestions.

2.3. Data Collection Procedure. In order to recognize the current situation and intentions of corporate sustainable product development under CSR, this study collected data using a questionnaire survey and in-depth interviews. The questionnaire design includes three parts. Part 1 was the subjects' basic information, Part 2 was an investigation of the current sustainable development situation, and Part 3 was an investigation of sustainable product development intentions. The questionnaire aimed to determine the factors of the corporate subjects' sustainable product development under CSR with the purpose that acquiring factors of sustainable product development can explore relationship between the current situation of sustainable product development and the increase of intention by corporate researchers. Finally, 


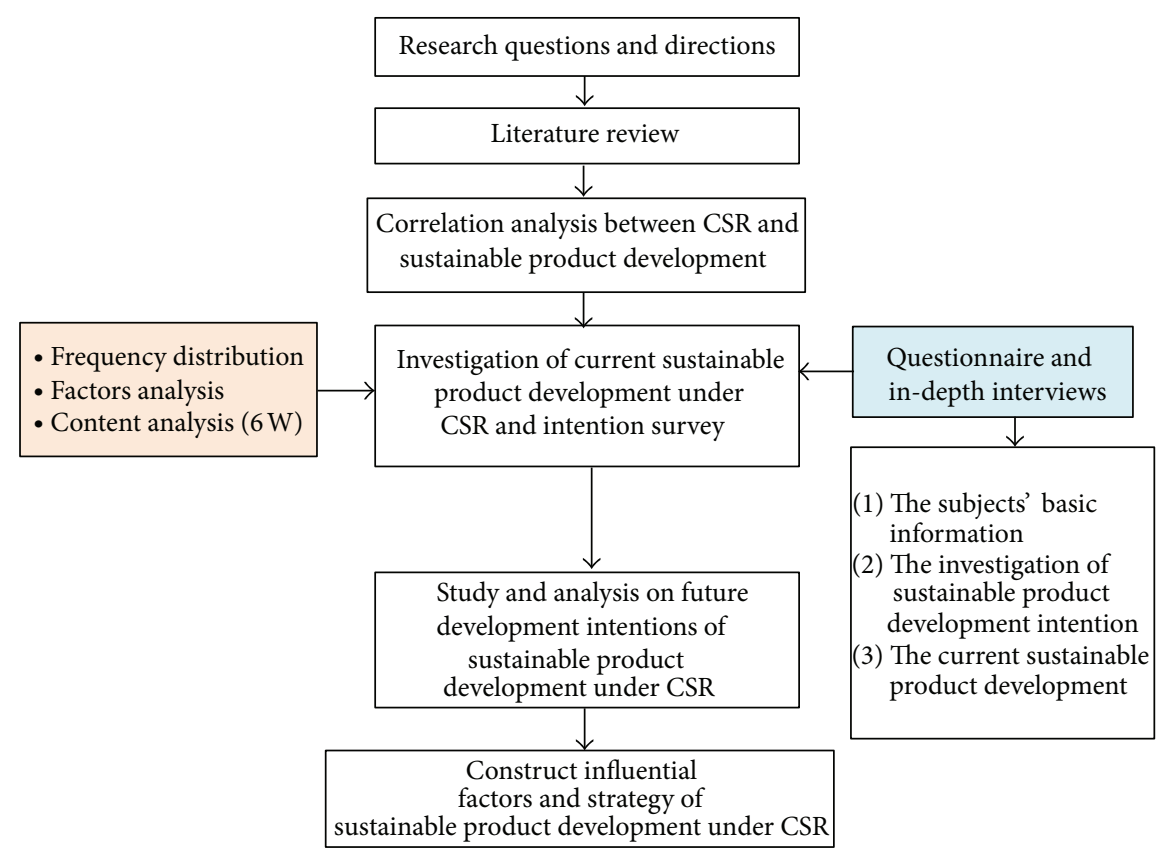

FIGURE 1: Research structure.

TABLE 1: Research subjects' backgrounds.

\begin{tabular}{|c|c|c|c|c|c|}
\hline No. & Name of corporation/council & Subjects & People & Years & Specialty \\
\hline \multirow{2}{*}{1} & \multirow{2}{*}{ ASUS } & Product designers & 2 & 10 and 12 & Product development and design \\
\hline & & Managers & 1 & 10 & Product marketing \\
\hline \multirow{2}{*}{2} & \multirow{2}{*}{ Chi Mei Optoelectronics Corporation } & Product designers & 1 & 8 & Product development and design \\
\hline & & Managers & 1 & 12 & Product marketing and plan managemen \\
\hline \multirow{2}{*}{3} & \multirow{2}{*}{ HP } & Product designers & 1 & 10 & Product development and design \\
\hline & & Managers & 1 & 15 & Product marketing \\
\hline 4 & al Council for Sustainable Development Network & Director & 1 & 9 & Sustainable development strategy \\
\hline
\end{tabular}

this study developed the factor analysis as a resource of sustainable product development to be used as a reference for future coping models of corporate sustainable product development.

2.4. Data Analysis. After collecting data using the above methods, in order to thoroughly recognize the corporate subjects' views toward sustainable product development under CSR and the current situation, this study adopted SPSS to analyze the data of the questionnaire survey and conduct frequency distribution and principal component analysis. The analysis was based on 18 items of sustainable product development intention (Table 2). This study extracted the impact factors of sustainable product development intention, acquired their weights and rankings using SPSS, and recognized the implied design development points from the data.

In order to thoroughly interpret the interviews with the enterprises, this study conducted content analysis, which is a research method that uses objective, systematic, and quantitative descriptions of the content. It includes the characteristics of objectivity, systematicness, quantitativeness, and manifestness [21]. Consider the following.

(1) Objectivity. Data interpretation and coding do not totally rely on the researcher's explanation. They are based on consistent and systematic rules in order to guarantee the consistent results of different persons at different times.

(2) Systematicness. The main purpose is to show the truth. It is the other side of objectivity. The research step design should be based on precise rules. With systematic coding rules, research reliability can be guaranteed.

(3) Quantitativeness. The text can be transformed into figures. In other words, qualitative data is transformed into quantitative data. Quantitative applications are based on the measurements and items which are 
TABLE 2: Questions of sustainable product development intention.

\begin{tabular}{ll}
\hline No. & Questions \\
\hline 1 & In the development of all products, sustainable development is the priority. \\
3 & Besides product costs, product profits, environmental protection, and maximum social welfare are secondary concerns. \\
4 & Sustainable product development makes products different. \\
5 & To identify with the view that sustainable design is valuable. \\
6 & Sustainable design products are developed since the quality is guaranteed. \\
7 & Products are developed for sustainable design. \\
8 & Sustainable products are developed for CSR. \\
9 & When prices are the same, products of sustainable design will be developed. \\
10 & The sustainability of products is not important. We only develop products with the highest profits. \\
11 & Firms will develop the products because of the sustainability. \\
12 & The main value of your sustainable products is profit. \\
13 & The main values of sustainable products are based on environmental protection and social welfare. \\
14 & The increase of sustainable product development intention is based on governmental laws and corporate development planning. \\
15 & The concern is the practicability of products and pollution, and the sustainability of products is not important. \\
16 & Brand image will influence your sustainable development. \\
17 & The increase of sustainable product development intention is based on the increase of talents and professional knowledge. \\
18 & The sustainable products differ from the design and products of other brands. \\
\hline
\end{tabular}

generally the frequency, percentage, chi-square value, and population tests, such as the $t$-test, regression, and factor analysis.

(4) Manifestness. It studies the content of propagation and the effect. Content can be implied by various symbols or words. In other words, something is hidden in the propagation. After the data are screened and interpreted, the hidden meanings will be shown.

The above characteristics matched the data analysis of this study. Thus, by content analysis of $6 \mathrm{~W}$, this study analyzed the qualitative data of the in-depth interviews. The content analysis and the $6 \mathrm{~W}$ were used to find the message to the receivers, why and how the message was sent, and the effect of the message (Table 3 ) in order to completely interpret the environmental backgrounds of the subjects and the meanings [22].

\section{Research Analysis and Results}

3.1. Intentions of Sustainable Product Development under CSR. In this study, a total of 12 questionnaires were distributed, and there were 12 returns. The principal component factor analysis technique is employed for extracting firms' factors of sustainable product development intention under CSR. Factor analysis is used to uncover the latent dimensions of a set of variables. It reduces attribute space from a larger number of variables to a smaller number of factors. The mathematical framework of the principal component factor analysis is to be presented as follows.
Assuming a set of $p$ new variables, each variable can be represented as a linear transformation of $q$ common factors $f_{j}$ and specific factors $\varepsilon_{i}$. Consider the following:

$$
\begin{gathered}
x_{1}=\mu_{1}+l_{11} f_{1}+l_{12} f_{2}+\cdots+l_{1 q} f_{q}+\varepsilon_{1}, \\
x_{2}=\mu_{2}+l_{21} f_{1}+l_{22} f_{2}+\cdots+l_{2 q} f_{q}+\varepsilon_{2}, \\
x_{3}=\mu_{3}+l_{31} f_{1}+l_{32} f_{2}+\cdots+l_{3 q} f_{q}+\varepsilon_{3}, \\
\vdots \\
x_{p}=\mu_{p}+l_{p 1} f_{1}+l_{p 2} f_{2}+\cdots+l_{p q} f_{q}+\varepsilon_{p},
\end{gathered}
$$

where $q<p$ and $l_{i j}$ is the factor loading which represents the loading or weights of the $i$ th variable on the $j$ th common factor, and it is given as follows:

$$
l_{i j}=\frac{w_{i j} \sqrt{\lambda_{j}}}{s_{i}},
$$

where $w_{i j}$ is the weights of the $i$ th variable on the $j$ th common factor, $\lambda_{j}$ is the eigenvalue of the $j$ th common factor, and $s_{i}$ is the standard deviation of the $i$ th variable. Factor loading represents the correlation between a specific observed variable and a specific factor, and higher value means a closer relationship.

The linear transformations as illustrated in (1) can be expressed in terms of matrix form as

$$
X=\mu+L F+\varepsilon
$$


TABLE 3: $6 \mathrm{~W}$ of content analysis.

\begin{tabular}{|c|c|c|}
\hline Item & Definition & Explanation \\
\hline Who & $\begin{array}{l}\text { Study on message } \\
\text { sources }\end{array}$ & The author's capability, characteristics or ideology, and value system. \\
\hline What & Message content & $\begin{array}{l}\text { To study the change of content in different places and at different times, as well as the relationship } \\
\text { between the authors' characteristics and content and the content matching external criteria. }\end{array}$ \\
\hline Whom & Message receiver & To find whether there are different propagation implications for different message receivers. \\
\hline How & $\begin{array}{l}\text { Skill of message } \\
\text { propagation }\end{array}$ & Subjects are not limited to words. \\
\hline What effect & Message effect & To study the effect after message propagation. \\
\hline Why & $\begin{array}{l}\text { Reason of message } \\
\text { propagation }\end{array}$ & To study the author's motives. \\
\hline
\end{tabular}

where

$$
\begin{gathered}
X=\left[\begin{array}{c}
x_{1} \\
x_{2} \\
x_{3} \\
\vdots \\
x_{p}
\end{array}\right], \quad, \quad \mu=\left[\begin{array}{c}
\mu_{1} \\
\mu_{2} \\
\mu_{3} \\
\vdots \\
\mu_{p}
\end{array}\right], \\
L=\left[\begin{array}{ccccc}
l_{11} & l_{12} & l_{13} & \cdots & l_{1 q} \\
l_{21} & l_{22} & l_{23} & \cdots & l_{2 q} \\
l_{31} & l_{32} & l_{33} & \cdots & l_{3 q} \\
\vdots & \vdots & \vdots & \ddots & \vdots \\
l_{p 1} & l_{p 2} & l_{p 3} & \cdots & l_{p q}
\end{array}\right], \\
F=\left[\begin{array}{c}
f_{1} \\
f_{2} \\
f_{3} \\
\vdots \\
f_{p}
\end{array}\right], \\
\end{gathered}
$$

The matrix $L$ is called the factor loading matrix or factor pattern matrix. Meanwhile, the following assumptions are defined:

$$
\begin{array}{ll}
E(F)=0, & \operatorname{Cov}(F)=\Phi, \\
E(\varepsilon)=0, & \operatorname{Cov}(\varepsilon)=\Psi
\end{array}
$$

$$
\operatorname{Cov}(F, \varepsilon)=0,
$$

where specific factors $\varepsilon_{i}, i=1,2, \ldots, p$, are assumed uncorrelated and the expected values are 0 such that $E\left(\varepsilon_{i}\right)=$ 0 , for all $i$. The variances of these specific factors can be defined as the normal distribution of $\psi_{i}, i=1,2, \ldots, p$, such that

$$
\Psi=\left[\begin{array}{ccccc}
\psi_{1} & 0 & 0 & \cdots & 0 \\
0 & \psi_{2} & 0 & \cdots & 0 \\
0 & 0 & \psi_{3} & \cdots & 0 \\
\vdots & \vdots & \vdots & \ddots & \vdots \\
0 & 0 & 0 & \cdots & \psi_{p}
\end{array}\right]
$$

For the common factors, $\operatorname{Cov}(F)$ is the covariance matrix and is equal to

$$
\begin{aligned}
\operatorname{Cov}(F) & =\sigma(F, F)=E\left(F F^{T}\right) \\
& =\Phi=\left[\begin{array}{ccccc}
\phi_{11} & \phi_{12} & \phi_{13} & \cdots & \phi_{1 q} \\
\phi_{21} & \phi_{22} & \phi_{23} & \cdots & \phi_{2 q} \\
\phi_{31} & \phi_{32} & \phi_{33} & \cdots & \phi_{3 q} \\
\vdots & \vdots & \vdots & \ddots & \vdots \\
\phi_{q 1} & \phi_{q 2} & \phi_{q 3} & \cdots & \phi_{q q}
\end{array}\right],
\end{aligned}
$$

where $F^{T}$ is the transpose of the vector $F$. Generally, vector $\mu$ is assumed to be 0 , the common factors $f_{i}, i=1,2, \ldots, q$, are assumed to be uncorrelated, and the variance of each factor is 1 since the variance is a special case of the covariance when the two variables are identical such that $\sigma(F, F)=\sigma^{2}(F)$ and $\Phi=I$, where $I$ is an identity matrix.

Similarly, the covariance matrix of the new variables can be defined as [23]

$$
\begin{aligned}
\operatorname{Cov}(X) & =\sigma(X, X)=E\left(X X^{T}\right) \\
& =E\left[(L F+\varepsilon)(L F+\varepsilon)^{T}\right] \\
& =E\left[L F(L F)^{T}+\varepsilon(L F)^{T}+L F \varepsilon^{T}+\varepsilon \varepsilon^{T}\right] \\
& =L E\left(F F^{T}\right) L^{T}+E\left(\varepsilon F^{T}\right) L^{T}+L E\left(F \varepsilon^{T}\right)+E\left(\varepsilon \varepsilon^{T}\right) \\
& =L \Phi L^{T}=\left[\begin{array}{ccccc}
\sigma_{1}^{2} & 0 & 0 & \cdots & 0 \\
0 & \sigma_{2}^{2} & 0 & \cdots & 0 \\
0 & 0 & \sigma_{3}^{2} & \cdots & 0 \\
\vdots & \vdots & \vdots & \ddots & \vdots \\
0 & 0 & 0 & \cdots & \sigma_{p}^{2}
\end{array}\right]
\end{aligned}
$$

where $\sigma_{i}^{2}, i=1,2, \ldots, p$, are the eigenvalues $\lambda_{i}, i=$ $1,2, \ldots, p$, of covariance matrix $\operatorname{Cov}(F)$, which represent the contribution of the common factors to the new variables.

Based on the discussion presented in the previous paragraphs, the common factor extracting criterion adopted 
TABLE 4: Factors of sustainable product development intention under CSR.

\begin{tabular}{lccc}
\hline Names of factors & Eigenvalues & Variance explained (in \%) & Number \\
\hline Sustainable development purpose & 5.930 & 22.964 & 6.8 .10 .12 .13 .17 \\
Corporate development purpose & 4.205 & 18.724 & 2.7 .14 .15 .18 \\
Corporate sustainable development & 2.766 & 17.350 & 1.4 .9 \\
Sustainable development value & 2.028 & 14.188 & 3.11 \\
Sustainable development activity & 1.498 & 11.303 & 16.6 \\
Sustainable product quality & 1.334 & 8.948 & 5 \\
\hline
\end{tabular}

is called the Kaiser criterion which decides the principal components for use by simply selecting the factors with greater than 1 eigenvalues. Consequently, 6 most influential factors are extracted from 18 items of sustainable product development intention as the common factors which participate in further analysis.

In order to facilitate the interpretation of these extracted components that are considered relevant, a rotation procedure which is essential in giving factors meaning is usually followed. The rotating approach has been suggested as it simplifies the component structure and therefore makes its interpretation easier and more reliable. The rotation can be explained as a variety of methods used to further analyze initial components, aiming to make the pattern of loadings clearer and more well-defined, thus revealing a simple structure of the initial information [24]. Among the rotation approaches, Promax rotation method is much more efficient, and it is commonly applied on the large factoring processes.

The Promax rotation with Kaiser normalization and a Kappa parameter of 4 is employed in this research. The Promax rotation computes best orthogonal solution and then relaxes orthogonality constraints to gain simplicity in the interpretation. The amount of relaxation is determined by a parameter called Kappa. The Kappa value of 4 was adopted as it is the most efficient amount of rotation that allows the factors to be correlated [25].

To rotate a factor pattern is to apply a nonsingular linear transformation to the unrotated factor pattern matrix. An optimal transformation is usually defined as a minimization or maximization procedure of a simplicity function. For the Promax rotation, the simplicity function employed is the sum of squared differences between the rotated factor pattern and the target matrix in which the entries are raised to some power (typically between 2 and 4 ) to make the structure of the loadings become bipolar. The optimal transformation is obtained by minimizing this simplicity function with respect to the choices of all possible transformations [26]. The simplicity function being optimized can be defined as [27]

$$
f=c_{1}(H-Q)+c_{2}(V-Q)
$$

where

$$
\begin{gathered}
H=\sum_{i}\left(\sum_{j} b_{i j}^{2}\right)^{2}, \quad V=\sum_{j}\left(\sum_{i} b_{i j}^{2}\right)^{2}, \\
Q=\sum_{j} \sum_{i} b_{i j}^{4},
\end{gathered}
$$

and $c_{1}$ and $c_{2}$ are constants, $b_{i j}$ represents an element of the rotated pattern matrix, $(H-Q)$ represents variable (row) parsimony, and $(V-Q)$ represents factor (column) parsimony. Thus, the relative importance of both the variable parsimony and the factor parsimony is adjusted using the constants $c_{1}$ and $c_{2}$ [27]. For rotations with Kaiser normalization, the definition of $b_{i j}$ is replaced by $b_{i j} / h_{i}$, where $h_{i}$ is the communality estimate of the $i$ th variable and is given as follows:

$$
h_{i}^{2}=l_{i 1}^{2}+l_{i 2}^{2}+\cdots+l_{i q}^{2}=\sum_{j=1}^{q} l_{i j}^{2} .
$$

As shown in (11), communality is the total influence on a single observed variable from all of the factors associated with it. It is equal to the sum of all the squared factor loadings for all of the factors related to the observed variable as defined in (11).

It can be discovered that, in oblique rotation such as Promax rotation, both a factor pattern matrix and a structure matrix are obtained. The structure matrix is simply the factor loading matrix as in orthogonal rotation, representing the variance in a measured variable explained by a factor on both unique and common contributions basis. Therefore, the factors with factor loading above the threshold of 0.4 are adopted and are given factors meanings in this study.

On the other hand, total variance explained indicates how much of the variability in the data has been modeled by the extracted factors. It can be discovered that the factor loadings for the principal component factor analysis are larger in absolute values as are the communalities, and, as a consequence, the total variance explained is also greater. The performed analysis has demonstrated that the cumulative total variance explained is $86.457 \%$.

Employing SPSS and principal component factor analysis, this study extracted the firms' factors of sustainable product development intention under CSR, which were based on 18 items of sustainable product development intention. The results are illustrated in Table 4. As demonstrated in Table 4, the researchers Zaltman and Burger [28] have suggested that, as long as the eigenvalues of selected factors are greater than 1 , the factor loadings in absolute values are over 0.30 , the cumulative total variance explained is above $40 \%$, and the obtained results of the factor analysis are feasible. Therefore, the obtained analysis results have demonstrated the feasibility of this study.

Based on the above data analysis, the impact factor rankings of the firms' sustainable product development intention 
TABLE 5: Factors of sustainable development purpose.

\begin{tabular}{llr}
\hline Number & Questions of sustainable product development intention & Factor coefficient \\
\hline 06 & Products are developed for sustainable design. & 0.851 \\
08 & When prices are the same, products of sustainable design will be developed. & 0.837 \\
10 & Firms will develop the products because of the sustainability. & 0.779 \\
12 & The main values of sustainable products are based on environmental protection and social welfare. & 0.746 \\
13 & The increase of sustainable product development intention is based on governmental laws and & 0.653 \\
17 & corporate development planning. & 0.463 \\
\hline
\end{tabular}

TABLE 6: Factors of corporate development purpose.

\begin{tabular}{lll}
\hline Number & Questions of sustainable product development intention & Factor coefficient \\
\hline 02 & $\begin{array}{l}\text { Besides product costs, product profits, environmental protection, and maximum social welfare are } \\
\text { secondary concerns. }\end{array}$ & 0.734 \\
07 & $\begin{array}{l}\text { Sustainable products are developed for CSR. } \\
\text { The concern is the practicability of products and pollution, and the sustainability of products is not }\end{array}$ & 0.748 \\
14 & important. & 0.673 \\
18 & Brand image will influence your sustainable development. & 0.673 \\
\hline
\end{tabular}

under CSR were as follows: (1) factors of sustainable development purpose; (2) factors of corporate development purpose; (3) factors of corporate sustainable development; (4) factors of sustainable development value; (5) factors of sustainable development activity; and (6) factors of sustainable product quality. Thus, according to the rankings, the key factor of sustainable product development for firms was sustainable development purpose, which refers to value-added services, profits, and brand image in the development. The second factor was corporate development purpose, which focuses on strategies of corporate development, governmental regulations, and international laws. The effect of manufacturing quality on development was the lowest. The factors were illustrated as follows.

(1) Factors of Sustainable Development Purpose. According to Table 5, the factors included six items. The results showed that the top three were the following: "06. Products are developed for sustainable design;" "08. When prices are the same, products of sustainable design will be developed;" and " 10 . Firms will develop the products because of the sustainability". The lowest was "17. The sustainable products differ from the design and products of other brands." Thus, based on the rankings, firms were concerned about the sustainable design of products the most. Table 7 lists the factors of the sustainability of products and prices, otherwise known as the sustainable development purpose.

(2) Factors of Corporate Development Purpose. According to Table 6 results of the factor analysis, the top four factors were the following: "07. Sustainable products are developed for CSR” (Factor coefficient 0.748); “02. Besides product costs, product profits, environmental protection, and maximum social welfare are secondary concerns" (Factor coefficient
0.734); "15. Brand image will influence your sustainable development" (Factor coefficient 0.673); and "14. The concern is the practicability of products and pollution, and the sustainability of products is not important" (Factor coefficient 0.673). The lowest factor was " 18 . In the era of CSR, the value of sustainable product design is the most significant" (Factor coefficient 0.435). According to the rankings, the firms focused on the image value of sustainable product development based on CSR. Besides the product costs, profits, environmental protection, and maximum social welfare were secondary concerns. This is known as the corporate development purpose.

(3) Factors of Corporate Sustainable Development. According to Table 7 factor analysis results, the top two factors were the following: "04. To identify with the view that sustainable design is valuable" (Factor coefficient 0.802), and "01. In the development of all products, sustainable development is the priority" (Factor coefficient 0.708 ). The lowest factor was "09. The sustainability of products is not important. We only develop products with the highest profits" (Factor coefficient 0.417 ). Thus, according to the rankings, the firms identified with the value of sustainable design, and they treated sustainable development as the priority. This is known as corporate sustainable development.

(4) Factors of Sustainable Development Value. According to Table 8 factor analysis results, the top two factors were the following: "18. In the era of CSR, the value of sustainable product design is the most significant" (Factor coefficient 0.802) and "03. Sustainable product development makes products different" (Factor coefficient 0.708). The lowest factors were the following: "11. The main value of your sustainable products is profit" (Factor coefficient 0.417 ) and "14. The concern is 
TABLE 7: Factors of corporate sustainable development.

\begin{tabular}{llr}
\hline Number & Questions of sustainable product development intention & Factor coefficient \\
\hline 01 & In the development of all products, sustainable development is the priority. & 0.708 \\
04 & To identify with the view that sustainable design is valuable. & 0.802 \\
09 & The sustainability of products is not important. We only develop products with the highest profits. & 0.417 \\
\hline
\end{tabular}

TABLE 8: Factors of sustainable development value.

\begin{tabular}{llr}
\hline Number & Questions of sustainable product development intention & Factor coefficient \\
\hline 03 & Sustainable product development makes products different. & 0.708 \\
11 & The main value of your sustainable products is profit. & 0.417 \\
14 & The concern is the practicability of products. Pollution and the sustainability of products are not important. & 0.417 \\
18 & In the era of CSR, the value of sustainable product design is the most significant. & 0.802 \\
\hline
\end{tabular}

the practicability of products. Pollution and the sustainability of products are not important" (Factor coefficient 0.417). According to the rankings, the firms suggested that, in the era of CSR, the value of sustainable product development is the most significant. Sustainable product development makes products different. This is known as the sustainable development value.

(5) Factors of Sustainable Development Activity. According to Table 9 factor analysis results, the top factor was: "16. The increase of sustainable product development intention is based on the increase of talents and professional knowledge" (Factor coefficient 0.501). The lowest factor was "06. Products are developed for sustainable design" (Factor coefficient 0.428 ). Thus, according to the rankings, the firms were concerned about professional knowledge of sustainable development and the increase of talents. This is known as sustainable development activity.

(6) Factors of Sustainable Product Quality. According to Table 10 factor analysis results, the top factor was "05. Sustainable design products are developed since the quality is guaranteed" (Factor coefficient 0.768). The lowest factor was "03. Sustainable product development makes products different" (Factor coefficient 0.423). Thus, according to the rankings, the firms considered sustainable products as a guarantee of quality. This is known as sustainable product quality. Consider the following.

3.2. Effects of Sustainable Product Development under CSR. This study adopted a literature review and interviews to generalize eight results of sustainable product development under CSR by content analysis of $6 \mathrm{~W}$. The content analysis is shown in Table 11.

(1) CSR aims to change firms' past profit-oriented concepts and suggests that it is good for firms to develop products according to the new concept of sustainable development. However, their concerns are prices, profit ratio, environmental protection, necessities, market demand, and recycling.

(2) Certification of sustainable product seals is influential and should be concerned about the requirements of regulations, cooperation of industrial chains, cost, and quality. Thus, regarding consumption, the functional and intrinsic value of products can be more important than the priority of sustainable products. Therefore, during development, firms should be concerned with the functions and added value of products, as well as environmental materials, security, human factor engineering, maintenance (reduction of waste), and so forth.

(3) Firms are essentially business units; thus, when developing new product, they must treat profits as the priority instead of CSR. However, in the product development process, design and development can be changed according to various factors. Thus, in the introduction of sustainable product development, the factor of firms' maximum profits will be overall manufacturing, materials, supply chains, and design processes. The concept of CSR can be introduced during this process.

(4) CSR relatively influences sustainability and manufacturing processes of products. However, as suggested above, it depends on firm managers to include environmental protection in the development and manufacturing processes in order to meet related regulations. Thus, in design and development, such regulations will encounter more obstacles. The construction of brands and corporate responsibilities are important indicators of CSR.

(5) Brand value is the main purpose for firms to develop CSR. Therefore, effects on consumers' identification and demand indirectly enhance firms' sustainable product development; however, implementation can be difficult. Corporate transportation should not rely on a single execution. Sustainable development can be implemented by guidance and assistance of government.

(6) Construction of corporate brand image, word-ofmouth brands of sustainable products, construction of products, and service quality are the key factors of consumers' opinions of sustainable products; thus, 
TABLE 9: Factors of sustainable development activity.

\begin{tabular}{llr}
\hline Number & Questions of sustainable product development intention & Factor coefficient \\
\hline 06 & Products are developed for sustainable design. & 0.428 \\
16 & $\begin{array}{l}\text { The increase of sustainable product development intention is based on the increase of talents and } \\
\text { professional knowledge. }\end{array}$ & 0.501 \\
\hline
\end{tabular}

TABLE 10: Factors of sustainable product quality.

\begin{tabular}{llr}
\hline Number & Questions of sustainable product development intention & Factor coefficient \\
\hline 05 & Sustainable design products are developed since the quality is guaranteed. & 0.768 \\
03 & Sustainable product development makes products different. & 0.423 \\
\hline
\end{tabular}

consumers perceive that the purpose of firms' development of sustainable products is to increase overall social benefits. In addition, consumers demand good bargains of less economic cost, which will be one of the critical issues in the future corporate developments.

(7) The basic factors for the development of sustainable products are technical support, cooperation of industrial chains, and economic benefits. The priority is to deal with the authority of product quality and business owners' concepts. Moreover, the effects of market demand and brand image should be of concern.

(8) Firms' current scope of sustainable development is limited to energy saving, environmental protection, recycling, environmental protection of materials, green manufacturing, maintenance, high added value, and so forth, which are the dimensions of product development. However, the sustainability of overall corporate development is more important. In other words, CSR will be the future trend.

3.3. Influential Factors and Strategy of Sustainable Product Development under CSR. After extracting the factors of sustainable product development intention under CSR and developing the rankings (Table 4), based on the impact factors and in-depth interviews, this study extracted the internal and external major factors of sustainable product development intention under CSR. This could help corporate development decision makers to make the best decision model in sustainable product development according to the factors. In general, corporate development decision models are based on product materials, profits, and costs as the criteria of development decisions. By introducing factors of sustainable product development under CSR generated by this study, the major factors of corporate sustainable product development could be developed. According to Figure 2, in the sustainable development purpose of sustainable product development intention under CSR, the major factors of corporate internal development intention were the reduction of actual costs, the enhancement of corporate image, and the added value for products. The major factor of corporate external development intention was the application for governmental subsidies. As to the corporate development purpose, the major factors of corporate internal development intention were corporate transformation actions and the construction of sustainable brands. The major factors of corporate external development intention were the corporate development strategy and restrictions of governmental laws. As to corporate sustainable development, the major factor of corporate internal development intention was the construction of internal concepts. The major factor of corporate external development intention was the promotion of sustainable development. As to the sustainable development value, the major factor of corporate internal development intention was the development of sustainable design. The major factor of corporate external development intention was future market demand. Regarding sustainable development activity, the major factors of corporate internal development intention were the development of sustainable design and the promotion of sustainable concepts. The major factor of corporate external development intention was the cooperation of the supply chains. Finally, as to the sustainable product quality, the major factors of corporate internal development intention were the innovation of product services and the enhancement of product quality. The major factor of corporate external development intention was innovation system construction.

According to the previously mentioned 18 main factors of corporate internal and external sustainable development intentions, as well as the interview content, the researcher obtained the internal factors of sustainable product development (Figure 3) and the external factors of sustainable product development (Figure 4) under CSR. As to sustainable product development under CSR, the internal decision factors referred to employee stimulation, image improvement, innovation capability, cost reduction, and quality enhancement. The external decision factors referred to law making and bans, market demand, social environment, supply chains (suppliers), and trading associations. Apparently, in the future, firms should promote sustainable concepts in the organizations, actively cultivate sustainable talents, and enhance employees' self-sustainability in order to encourage the employees. By the establishment of sustainable brands, firms can have an active transformation and effectively enhance their corporate image. They can promote sustainable design development and innovative product services and reinforce innovation capability. They can carefully consider the reduction of actual costs and increase the added value in 


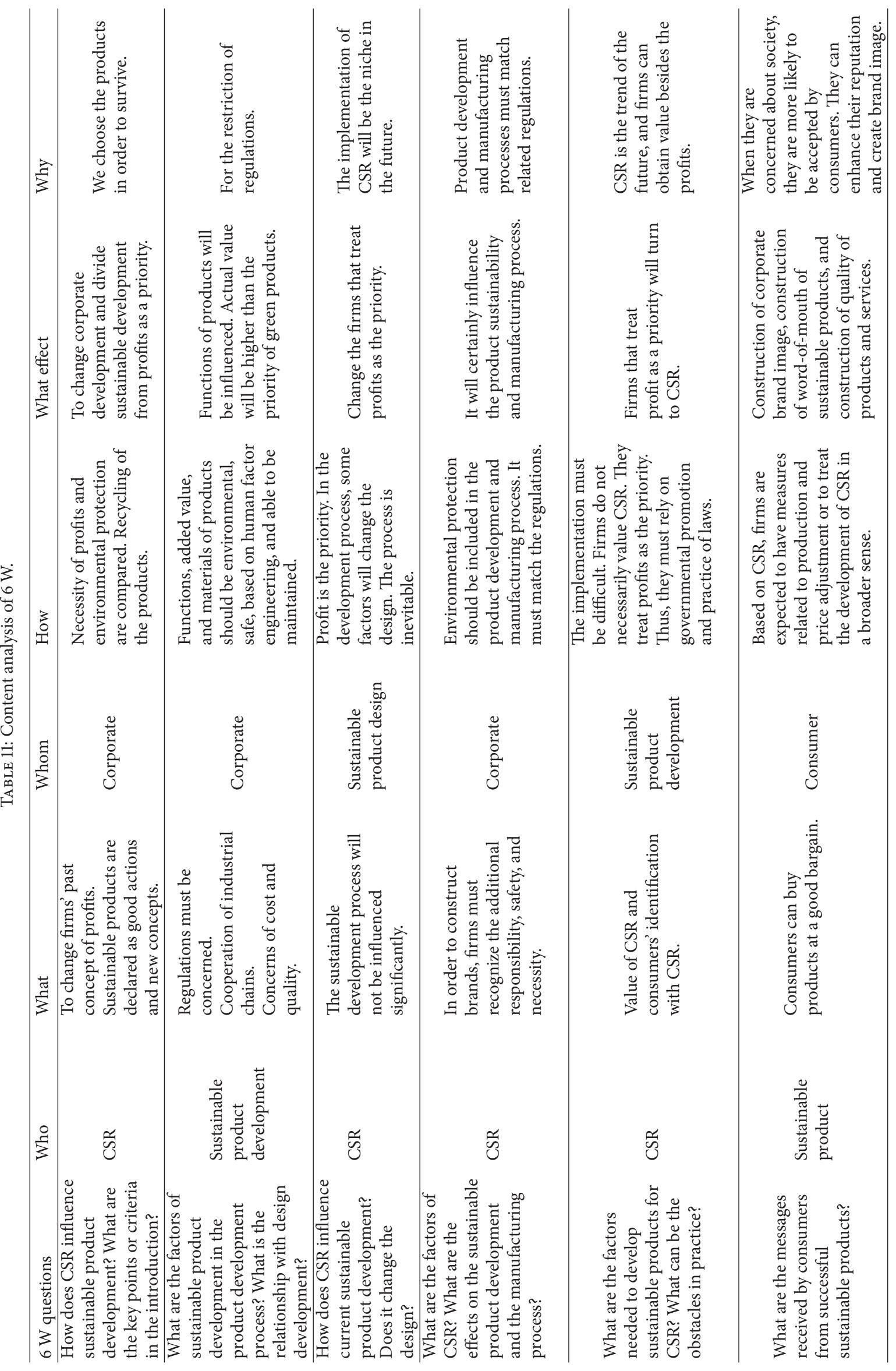




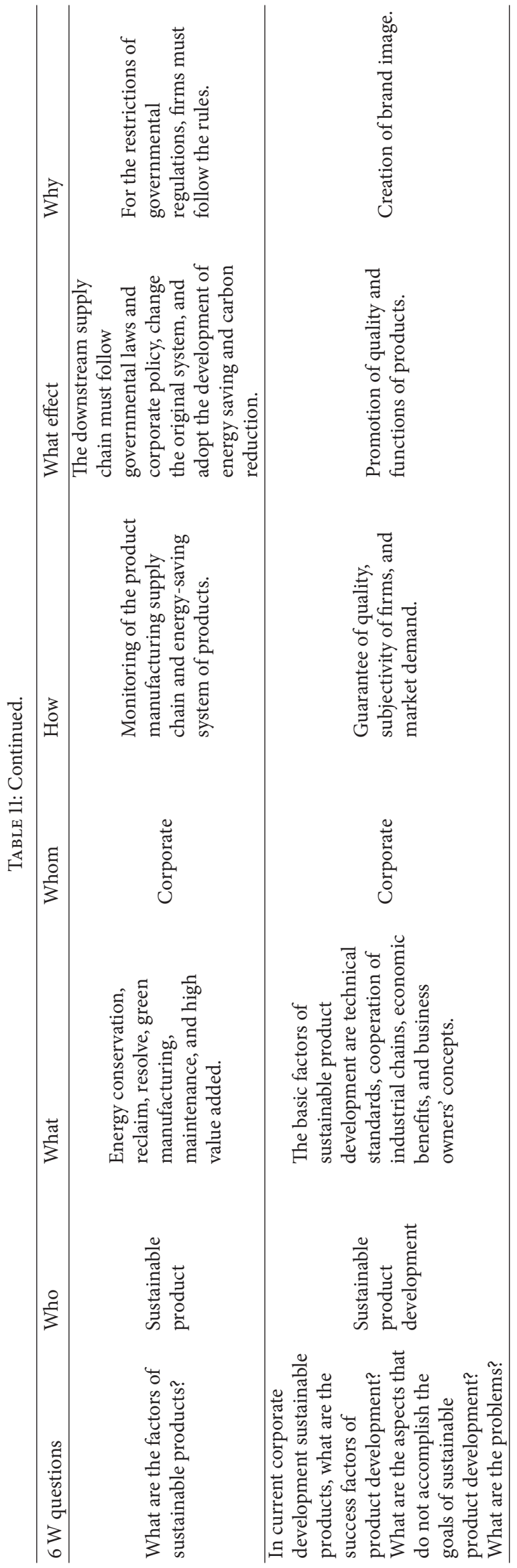




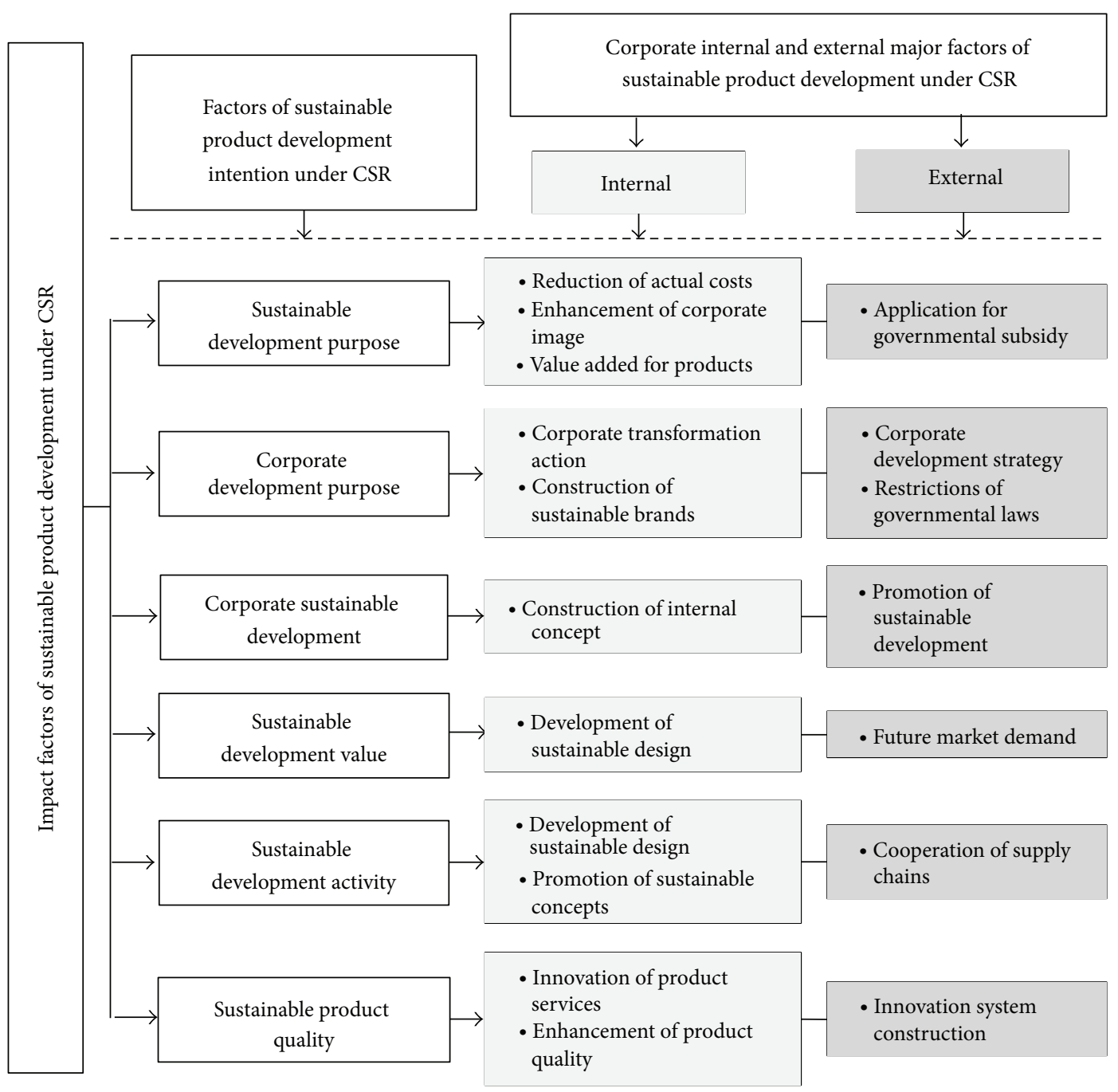

FIGURE 2: The impact factors of sustainable product development under CSR.

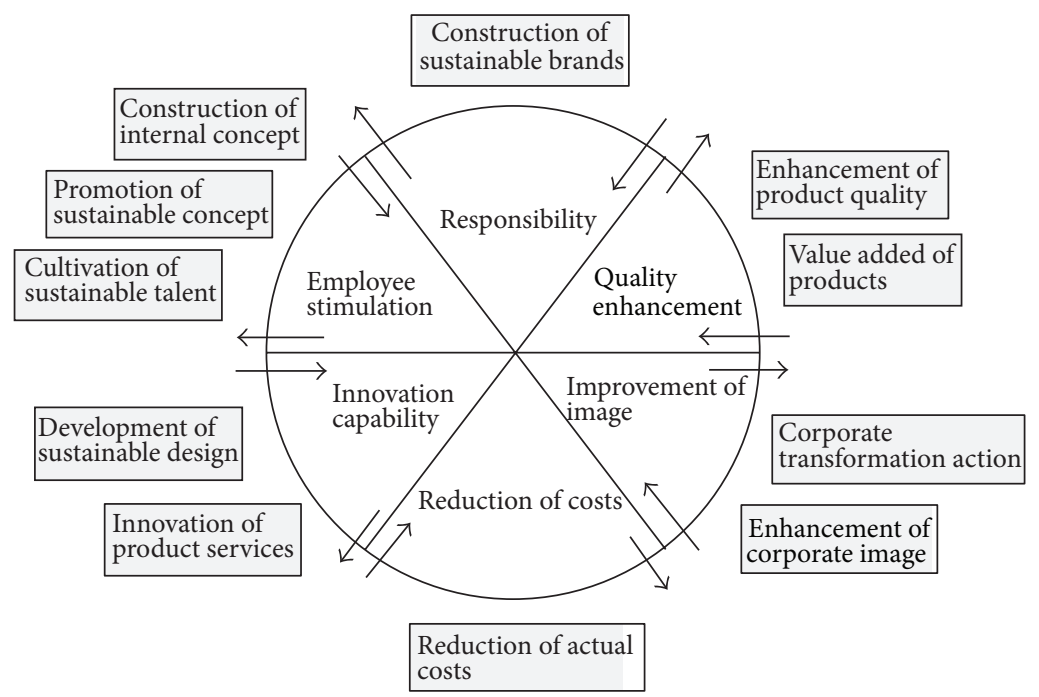

FIGURE 3: The internal factors of sustainable product development under CSR. 


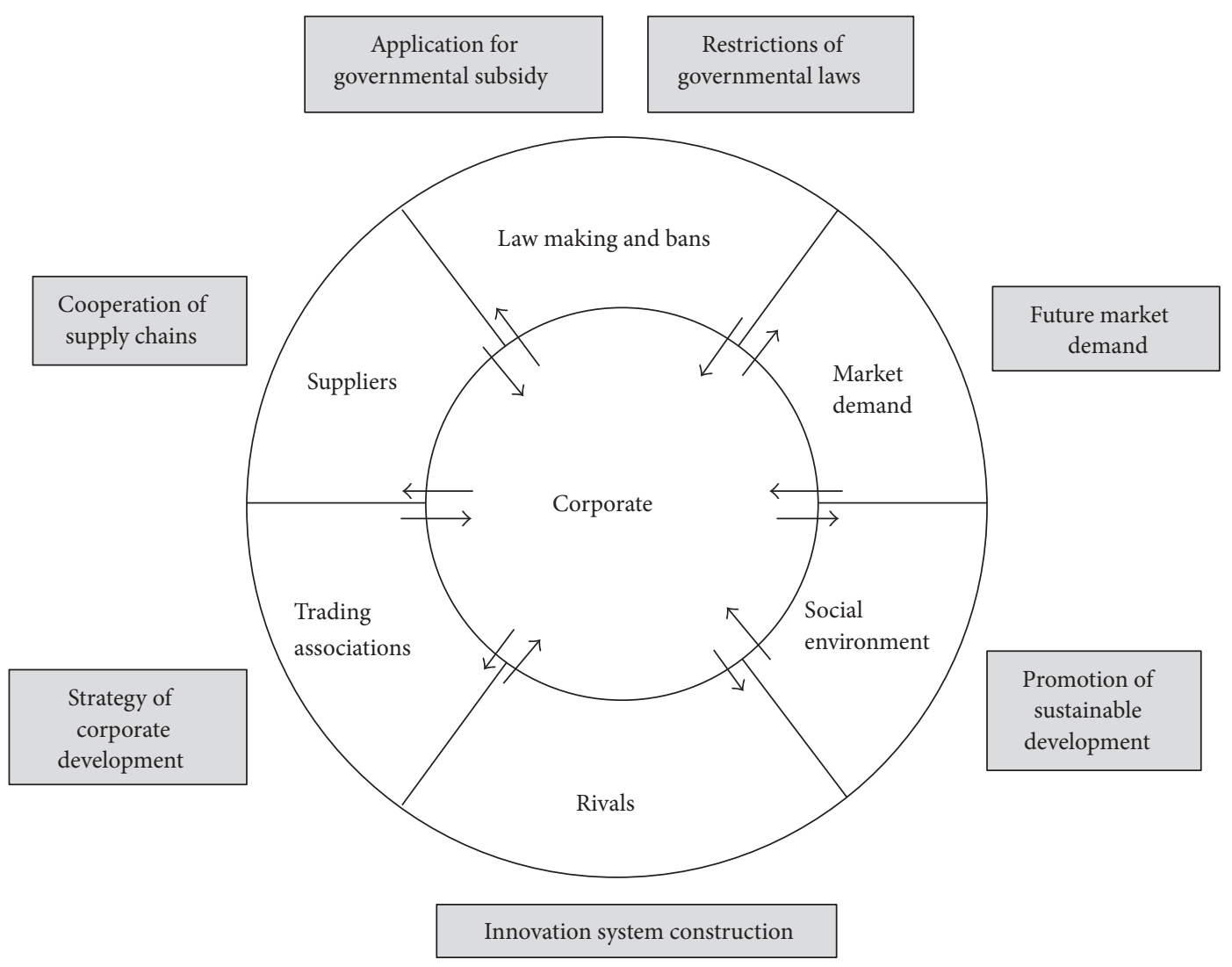

FIGURE 4: The external factors of sustainable product development under CSR.

order to save development costs. Finally, by improving product quality, overall corporate quality can be strengthened. In addition, firms rely on external factors, such as the implementation of governmental regulations and the applications for governmental subsidies. They can match future market demand and the overall supply chain to plan corporate sustainable development strategies, and they can actively implement innovation systems and sustainable development to accomplish sustainable product development under CSR.

\section{Conclusions}

With the rise of CSR, firms should pursue more sustainable operational rules. As to corporate development, sustainable product development has become the mainstream in the recent years. The reason is that the development of small and medium enterprises is rapid and prevailing. There are different types of corporate development. The effect of environmental change on convenience and efficiency on people is the most significant. However, due to the perspective of CSR and the uncertainty of sustainable development, firms' intention for sustainable product development is usually influenced. Apparently, environmental laws and corporate development strategy are the significant criteria of corporate sustainable development. If firms can effectively control these sustainable development factors, they will enhance their development intention for corporate sustainable development. This study expected that the coping model of sustainable product development constructed under CSR could serve as a reference for the sustainable development of small and medium enterprises in Taiwan. Based on the results, we conclude the paper with the following.

(1) Regarding current sustainable product development under CSR, firms must adjust development policies between sustainable development and profits to accomplish the goal of mutual benefits. It is suggested that, in sustainable development, firms should first be concerned about the requirement of laws, cooperation of industrial chains, cost, quality, and proper practice of incidents or activities of CSR. They can thus construct corporate brand image and word-ofmouth for sustainable products and quality service.

(2) Regarding sustainable product development intentions under CSR, firms concern about sustainable development purpose the most, meaning value added, profit, and brand image during development. The second is corporate development purpose, which emphasizes corporate development strategy, legal regulations of government, and international laws; the third is the concept of sustainable development, including employees' concepts of sustainability, which 
mostly refers to positive concepts of sustainable development.

(3) Regarding the trend of sustainable product development under CSR, internal corporate environment management and corporate sustainable development are moderated by attitude toward CSR, meaning a more active attitude. In addition, relationships between internal environment management and positive performance are influenced by attitudes toward CSR. Sustainable development performance is better, such as management, improvement of corporate internal environments, and enhancement of environmental performance, which can lower energy consumption, waste, and cost of fines for environmental accidents.

(4) In the development of sustainable business, firms can mainly practice internal reform with the support of external reform in order to cultivate sustainable talents, promote sustainable concepts, improve corporate image, follow the regulations, cooperate with the overall supply chain, follow corporate transformation development, and follow the responsive policies of governmental laws. As to CSR, the relationship between corporate internal environment management and corporate sustainable development is moderated by attitude toward CSR. Those with a more active attitude toward CSR have a better performance of sustainable development. In addition, the relationship between internal environment management and positive performance is influenced by the attitude toward CSR. When the attitude toward CSR is more active, there will be a more positive performance of sustainable development.

\section{References}

[1] I. C. Pirnea, M. Olaru, and C. Moisa, "Relationship between corporate social responsibility and social sustainability," Economy Transdisciplinarity Cognition, vol. 14, no. 1, pp. 36-43, 2011.

[2] U. Ubius and R. Alas, "The impact of corporate social responsibility on the innovation climate," Engineering Economics, vol. 23, no. 3, pp. 310-318, 2012.

[3] C. Y. Hsu, C. C. Liang, and F. Y. Ye, "Ownership structure and corporate social responsibility," in Proceedings of the Corporate Finance Academic Conference, National Kaohsiung First University of Science and Technology, Kaohsiung, Taiwan, May 2010.

[4] T. H. Koh and W. C. Fang, "The effects of corporate social responsibility on purchase intention: the mediating effects of brand attachment and brand image," Journal of Business Administration, vol. 94, pp. 41-68, 2012.

[5] A. Kolk and R. van Tulder, "International business, corporate social responsibility and sustainable development," International Business Review, vol. 19, no. 2, pp. 119-125, 2010.

[6] D. Krumwiede, A. M. Hackert, J. Tokle, and R. J. Vokurka, “The practice of corporate social responsibility in different countries: a study of firms in Canada, Hungary, Italy, Lebanon, Taiwan and the United States," International Journal of Management, vol. 29, no. 1, pp. 389-403, 2012.
[7] K.-T. Hsu, "The advertising effects of corporate social responsibility on corporate reputation and brand equity: evidence from the life insurance industry in Taiwan," Journal of Business Ethics, vol. 109, no. 2, pp. 189-201, 2012.

[8] National Council for Sustainable Development Network [NCSDN], 2007, http://nsdn.epa.gov.tw/INDEX.ASP.

[9] W. C. Wei and Y. H. Chuage, "An empirical study of the relationship among corporate social responsibility, corporate image, consumer's attitude and behavioral intentions," International Journal of Lisrel, vol. 2, no. 2, pp. 1-21, 2009.

[10] A. Lindgreen and V. Swaen, "Corporate social responsibility," International Journal of Management Reviews, vol. 12, no. 1, pp. $1-7,2010$.

[11] J. C. Tu and T. F. Kao, "Relationship between attitude toward green consumption and corporate social responsibility," Ling Tung Journal, vol. 30, pp. 73-110, 2011.

[12] G. Campopiano, A. de Massis, and L. Cassia, "The relationship between motivation and actions in corporate social responsibility: an exploratory study, International Journal of Business \& Society, vol. 13, no. 3, pp. 325-341, 2012.

[13] A. D. Jayal, F. Badurdeen, O. W. Dillon Jr., and I. S. Jawahir, "Sustainable manufacturing: modeling and optimization challenges at the product, process and system levels," CIRP Journal of Manufacturing Science and Technology, vol. 2, no. 3, pp. 144-152, 2010.

[14] C. Y. Hsu and C. C. Lin, "The impact of controlling shareholder on corporate social responsibility," in Proceedings of the Taiwan Conference on Business and Information, Graduate School of Information Management, Taipei University, Taipei, Taiwan, April 2011.

[15] B. Y. Zhou, "The correlation analysis between corporate social responsibility and corporate operating performance," Journal of Chinese Economic Research, vol. 10, no. 2, pp. 17-29, 2012.

[16] R. Virvilaite and U. Daubaraite, "Corporate social responsibility in forming corporate image," Engineering Economics, vol. 22, no. 5, pp. 534-543, 2011.

[17] J. Golovachev, O. Budde, and D. Kellmereit, “Technology and Innovation radars: effective Instruments for the development of a sustainable innovation strategy and successful product launches," International Journal of Innovation \& Technology Management, vol. 7, no. 3, pp. 229-236, 2010.

[18] C. Yu, C. C. Yu, Y. S. Cheng, T. F. Yu, and P. J. Lee, "A study of the relationships among employees' perception of corporate social responsibility, organizational commitment and turnover intention," Journal of National Taipei University of Technology, vol. 42, no. 2, pp. 147-173, 2009.

[19] A. B. Carroll and K. M. Shabana, "The business case for corporate social responsibility: a review of concepts, research and practice," International Journal of Management Reviews, vol. 12, no. 1, pp. 85-105, 2010.

[20] J. K. Hall, G. A. Daneke, and M. J. Lenox, "Sustainable development and entrepreneurship: past contributions and future directions," Journal of Business Venturing, vol. 25, no. 5, pp. 439448, 2010.

[21] M. W. DiStaso and D. S. Bortree, "Multi-method analysis of transparency in social media practices: survey, interviews and content analysis," Public Relations Review, vol. 38, no. 3, pp. 511$514,2012$.

[22] L. Yang, Z. G. Hu, J. Long, and T. Guo, "Ontology modeling and semantic information service of expert domain," Journal of Chinese Computer Systems, vol. 8, pp. 1730-1735, 2012. 
[23] W. J. Krzanowski, Principles of Multivariate Analysis, vol. 3 of Oxford Statistical Science Series, chapter 7.1, The Clarendon Press Oxford University Press, New York, NY, USA, 1988.

[24] V. Bountziouka and D. B. Panagiotakos, "The role of rotation type used to extract dietary patterns through principal component analysis, on their short-term repeatability," Journal of Data Science, vol. 10, no. 1, pp. 19-36, 2012.

[25] A. B. Costello and J. W. Osborne, "Best practices in exploratory factor analysis: four recommendations for getting the most from your analysis," Practical Assessment Research \& Evaluation, vol. 10, no. 7, pp. 1-9, 2005.

[26] R. I. Jennrich, "Standard errors for obliquely rotated factor loadings," Psychometrika, vol. 38, pp. 593-604, 1973.

[27] C. B. Crawford and G. A. Ferguson, "A general rotation criterion and its use in orthogonal rotation," Psychometrika, vol. 35, no. 3, pp. 321-332, 1970.

[28] G. Zaltman and P. Burger, Marketing Research: Fundamentals and Dynamics, Dryden Press, Hinsdale, Ill, USA, 1975. 


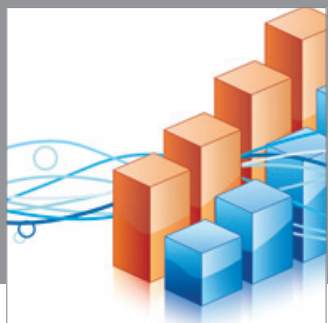

Advances in

Operations Research

mansans

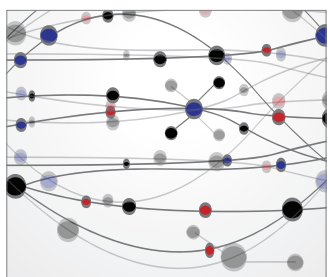

The Scientific World Journal
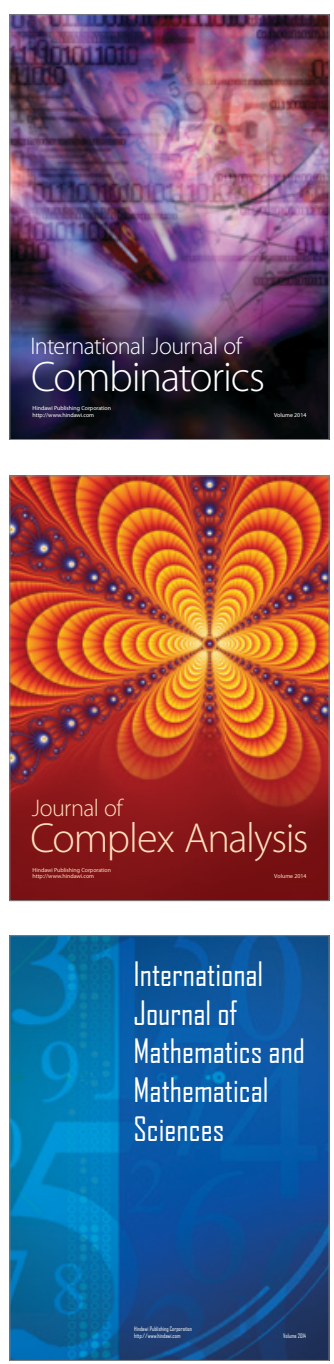
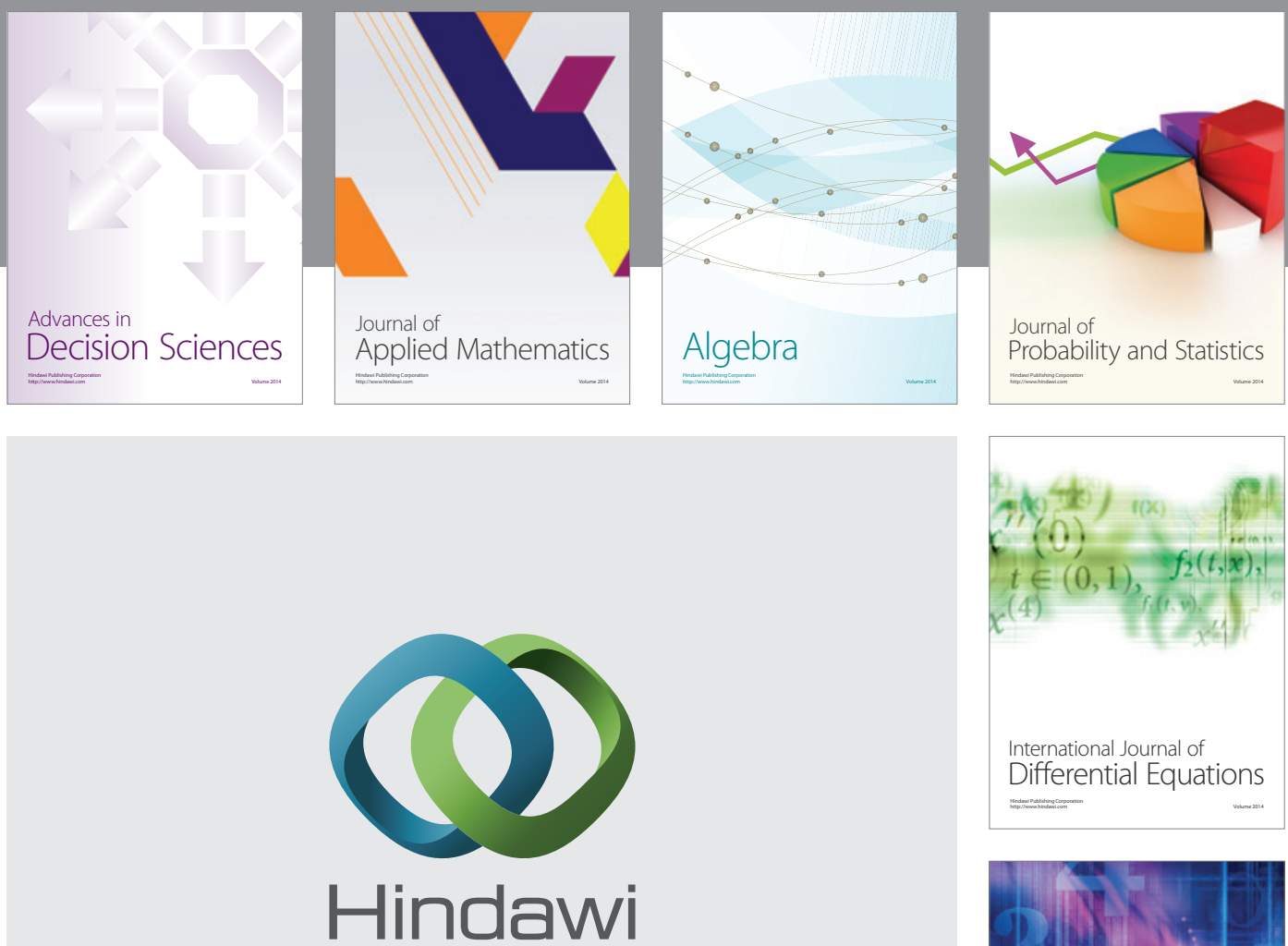

Submit your manuscripts at http://www.hindawi.com
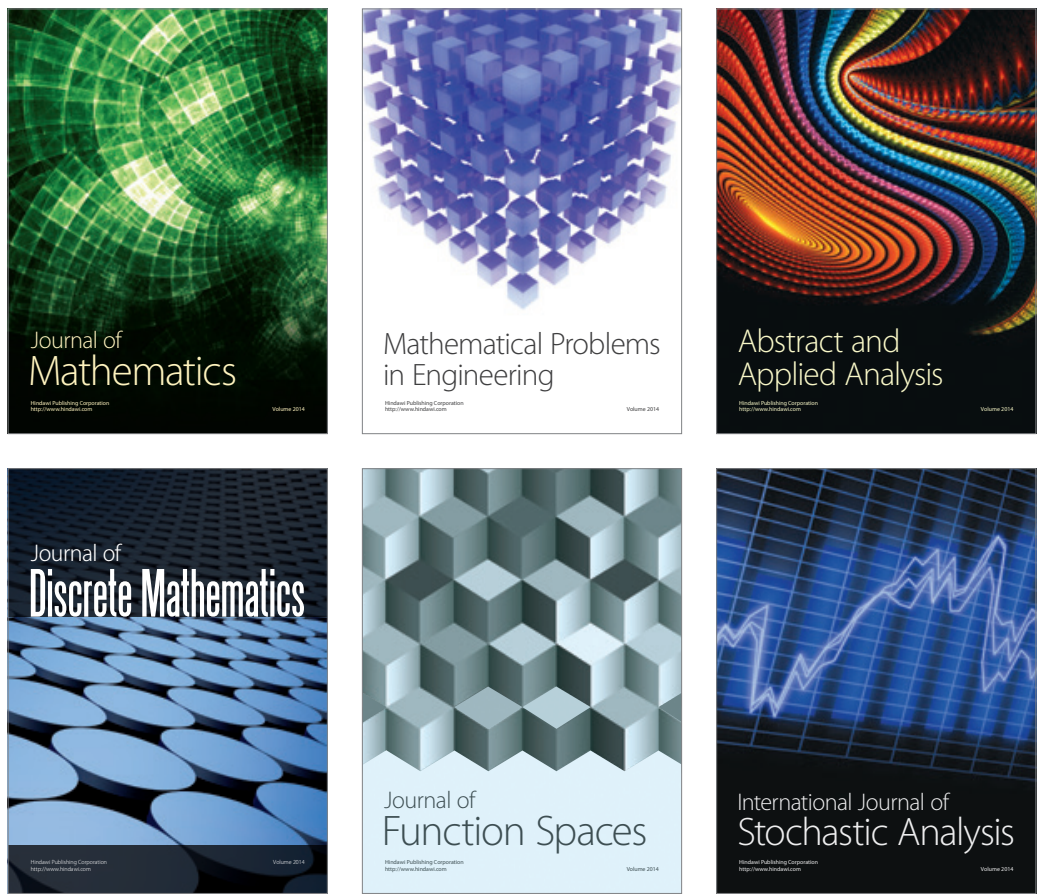

Journal of

Function Spaces

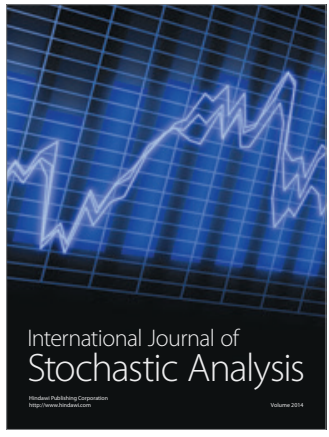

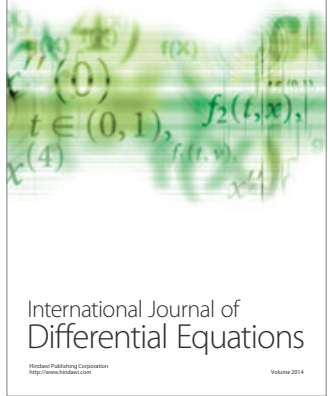
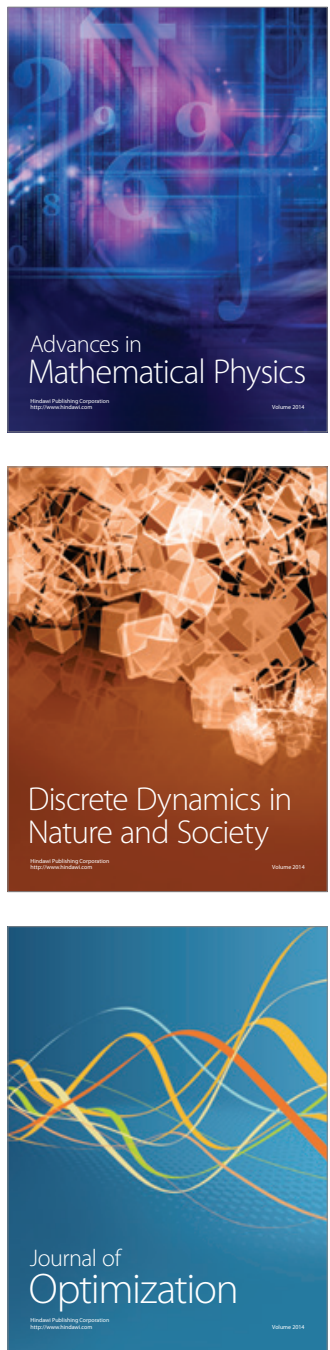